\title{
A Unified Model Considering Effects of Droplet Break-Up and Air Entrainment at the Initial Stage of Fuel Spray Penetration
}

\author{
S. Jafarmadar, ${ }^{1}$ B. Jalilpour, ${ }^{1}$ D. D. Ganji, ${ }^{2}$ and H. Taghavifar ${ }^{1}$ \\ ${ }^{1}$ Department of Mechanical Engineering, Faculty of Engineering, Urmia University, Urmia 57561-15311, Iran \\ ${ }^{2}$ Department of Mechanical Engineering, Babol University of Technology, P.O. Box 484, Babol, Iran \\ Correspondence should be addressed to B. Jalilpour; b.jalilpour@yahoo.com
}

Received 25 November 2013; Accepted 3 April 2014; Published 24 April 2014

Academic Editor: Bin Jiang

Copyright (c) 2014 S. Jafarmadar et al. This is an open access article distributed under the Creative Commons Attribution License, which permits unrestricted use, distribution, and reproduction in any medium, provided the original work is properly cited.

\begin{abstract}
This paper proposes a new unified single model that considers droplet break-up and air entrainment impact on three flow regimes (namely, Stokes, Allen, and Newton) in the initial stage of fuel spray penetration. Homotopy perturbation method was used to obtain semianalytical solutions of unified single model on diesel fuel's spray penetration when the influence of air entrainment is small (up to 0.1-0.2 ms after the start of injection). It is demonstrated that the applied analytical method is very straightforward in comparison with existing techniques. Furthermore, it is decidedly effectual in terms of accuracy and rapid convergence. The formulation of the problem is presented in the text as well as the analytical and numerical procedures.
\end{abstract}

\section{Introduction}

The importance of the spray penetration issue for various applications is well recognized and has been extensively studied experimentally and theoretically [1-5]. A rigorous theory of spray penetration would be very complex if it needs to involve the modeling of the ligaments formation and breakup, droplet break-up and evaporation, the air entrainment, and the turbulence effects [6]. A self-consistency of the modeling for all these processes is still a major challenge. However, this modeling is not always essential for understanding the process and engineering applications. On many occasions, it is so crucial to establish a "hierarchy" of the importance of the various processes and develop simplified models suitable for practical applications. In this manner, as mentioned in references $[7,8]$, simplified analytical models have been developed which describes the initial stage of spray penetration in three flow regimes, namely, Stokes, Allen, and Newton without considering the air entrainment influences.

The homotopy perturbation method is an effective approach for solving a wide class of applications [9-13]. It has been applied, for example, for solving the ordinary differential equations and partial differential equations [14-16], as well as for solving inverse problems [17-21].
The homotopy perturbation method has also been exploited for finding the exact and approximate solutions of the linear and nonlinear integral equations and their systems [22-24], the integrodifferential equations $[25,26]$, and the VolterraFredholm integral equation [27].

As can be seen in relevant literature, no attempt has been made so far to analytically study the effects of droplet break-up and air entrainment on the spray tip penetration. The objective of this paper is, therefore, firstly to construct a new unified model that considers the three flow regimes to consider the droplet break-up and air entrainment in the initial stage of fuel spray penetration. Secondly, an analytical result, which takes into account the flow regimes, is derived from homotopy perturbation method (HPM) employing Padé technique of the unified model. Thus, we utilize the homotopy perturbation method (HPM) as a powerful seriesbased analytical tool.

\section{The Initial Stage}

2.1. Dynamics of Droplets. The velocities of droplets injected from a nozzle exit tip are initially much greater than the velocity of the gas (air) stream but are slowed down due to 
the drag force, while gas is accelerated. The equation describing the dynamics of an individual droplet can be written as

$$
m_{d} \frac{d v_{d}}{d t}=-\frac{1}{2} C_{D} \rho_{g}\left(v_{d}-v_{g}\right)^{2} A_{d}
$$

where $m_{d}, v_{d}$, and $A_{d}$ are droplet's mass, velocity, and crosssectional area, respectively. $v_{g}$ and $\rho_{g}$ are gas velocity and density, respectively. In this study, only one-dimensional dynamics of gas and droplets are considered. $C_{D}$ is the drag coefficient, which depends on the shape of the droplet and the Reynolds number defined as $\operatorname{Re}=2 \rho_{g}\left(v_{d}-v_{g}\right) r_{d} / \mu_{g}$, with $r_{d}$ and $\mu_{g}$ being the droplet's radius and gas dynamic viscosity, respectively.

Assuming that the droplets are perfect spheres, then (1) is simplified as

$$
\frac{d^{2} s}{d t^{2}}=-\frac{3}{8} r_{d} C_{D} \frac{\rho_{g}}{\rho_{d}}\left(\frac{d s}{d t}-v_{g}\right)^{2}
$$

where $\rho_{d}$ represents the droplet's density, $s$ is the distance measured from the nozzle, and $v_{d}=d s / d t$. Equation (2) is not easily amenable to analytical results, especially due to the drag coefficient $C_{D}$, which is a rather complicated function of the Reynolds number. Therefore, a number of approximations for $C_{D}$ coefficient were suggested in the literature [7]. The most convenient approximation can be found in Douglas et al. [28], which considered three ranges of Reynolds numbers: $\operatorname{Re} \leq 0.2$ (Stokes flow), $0.2<\operatorname{Re} \leq 500$ (Allen flow), and $500<\operatorname{Re} \leq 10^{5}$ (Newton flow). The functions $C_{D}(\mathrm{Re})$ for these flows are given by the expressions: $C_{D}=24 / \operatorname{Re}$ (Stokes flow), $C_{D}=18.5 / \operatorname{Re}^{0.6}$ (Allen flow), and $C_{D}=0.44$ (Newton flow). The expressions for $C_{D}$ do not take into account the effects of droplet acceleration, internal circulation, vaporization, burning, nonspherical shape, vibrations, and heating processes.

Two basic approximations were applied to (1) in relation to $v_{g}$, namely, (i) $v_{g} \ll v_{d}$ and (ii) $v_{g}=k \sqrt{s}$, where $k=$ $\sqrt{K / r_{g 0}}$ and $K=3 r_{s}^{2} \alpha_{d} /\left(8 r_{d}\right) C_{D} v_{d 0}^{2}=$ constant. Here, $v_{d 0}$ is the initial droplet velocity, $r_{g}$ and $r_{s}$ are radii of the gas/air jet and the spray itself, respectively, $\alpha_{d}$ is the volume fraction of droplets in the spray, and $r_{g}$ is usually slightly larger than $r_{s}$, but as a first approximation we will assume that they are equal.

The approximate analytical results obtained from these approximations and their physical interpretations are extensively discussed in $[7,8]$.

Now with regard to the latter approximation for $v_{g}(=$ $k \sqrt{s}$ ) in (2), the governing equations for Stokes, Allen, and Newton flows $[7,29]$ are rewritten as follows:

$$
\begin{gathered}
\frac{d^{2} s}{d t^{2}}+\alpha \frac{d s}{d t}-\alpha k \sqrt{s}=0 \\
\frac{d^{2} s}{d t^{2}}+\beta\left(\frac{d s}{d t}\right)^{1.4}-1.4 \beta k \sqrt{s}\left(\frac{d s}{d t}\right)^{0.4}=0 \\
\frac{d^{2} s}{d t^{2}}+\gamma\left(\frac{d s}{d t}\right)^{2}-2 \gamma k \sqrt{s}\left(\frac{d s}{d t}\right)=0
\end{gathered}
$$

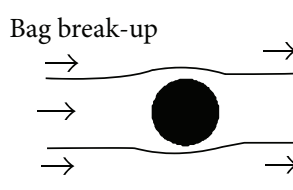

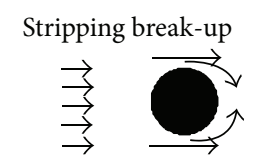

A
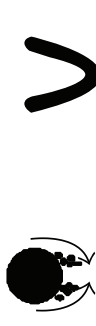

B
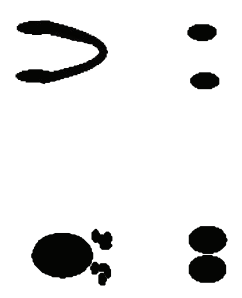

C

$\mathrm{D}$
FIGURE 1: Schematic illustration of a drop break-up caused by Rayleigh-Taylor (R-T) or Kelvin-Helmholtz (KH) instabilities.

where $\alpha=9 \mu_{g} / 2 r_{d}^{2} \rho_{d}, \beta=4.577 \mu_{g}^{0.6} \rho_{g}^{0.4} / r_{d}^{1.6} \rho_{d}$, and $\gamma=$ $0.165 \rho_{g} / r_{d} \rho_{d}$.

A careful examination of $(3 a),(3 b)$, and $(3 c)$ revealed that they could be combined to give the following model [30]:

$$
\frac{d^{2} s}{d t^{2}}+\alpha_{\eta}\left(\frac{d s}{d t}\right)^{\eta+1}-(\eta+1) k \alpha_{\eta} \sqrt{s}\left(\frac{d s}{d t}\right)^{\eta}=0 .
$$

Here $\eta$ denotes the flow regime parameter or identifier. Equation (4) is the unified model for the fuel spray penetration, and it has not been reported elsewhere in literature to the best of author's knowledge. The equation is nonlinear and includes all three regimes of the flow, in that the parameter $\eta$ takes the values $0,0.4$, and 1 , such that $\alpha_{0}=\alpha$ (Stokes flow), $\alpha_{0.4}=\beta$ (Allen flow), and $\alpha_{1}=\gamma$ (Newton flow), respectively.

2.2. Droplet Break-Up Models. A number of droplet breakup models have been proposed [1,31-33]. One of the most popular models is according to the comparison between the eigenfrequency of droplet oscillations and the frequency of turbulent pulsation in the surrounding gas. This allows the determination of the maximal stable droplet diameter. The predictions of this model are in good agreement with some experimental observations [34].

In our case, however, the driving force of droplet breakup is not the external turbulence, but the kinetic energy of the droplets themselves is. In this case, a different approach would seem to be more appropriate. As in [7], this study is based on the model developed in $[35,36]$ which is particularly attractive for analytical and numerical analysis and is widely used in CFD codes.

In this model, two droplet break-up regimes are identified and are shown in Figure 1. These are bag break-up assuming that

$$
\mathrm{We} \equiv \frac{\rho_{g} v_{d}^{2} r}{\sigma}>6
$$

And stripping break-up is as given assuming that

$$
Z \equiv \frac{\mathrm{We}}{\sqrt{\mathrm{Re}}}>0.5,
$$

where We is the Weber number and $s$ is the surface tension. The first regime is analogous to the Rayleigh-Taylor instability accompanied by the development of normal stresses. 
The second regime is analogous to the Kelvin-Helmholtz instability accompanied by the development of tangential stresses. The break-up processes described by (5) and (6) can occur simultaneously. In this case, the dominant process will be determined by the shortest lifetime as described below. Sometimes a more stringent criterion for the stripping instability $(Z>0.7)$ was applied [1]. The modifications of our analysis to meet this criterion would be straightforward. It is important not to confuse $Z$ with the Ohnesorge number, $\mathrm{Oh}(Z \equiv \sqrt{\mathrm{We}} / \mathrm{Re})[1]$. The lifetime of unstable droplets was estimated as [36]

$$
\begin{gathered}
t_{b}=D\left[\frac{\rho_{d} r^{3}}{2 \sigma}\right]^{1 / 2}, \\
t_{s}=c \frac{r}{v_{d}} \sqrt{\frac{\rho_{d}}{\rho_{g}}},
\end{gathered}
$$

where $D$ was considered equal to $\pi$ and $C=13$.

As a first approximation, the creation of droplets with different radii during the break-up process was not taken into account. The radii of unstable droplets are allowed to change continuously following the given equation by

$$
\frac{d r}{d t}=-\frac{r-r_{d b(s)}}{t_{b(s)}}
$$

where $t_{b}$ and $t_{s}$ were introduced by (7) and (8), respectively. $r_{d b(s)}$ is marginally stable radii that is determined by $\mathrm{We}=6$ and $Z=0.5$ conditions. This approximation can be explained by the fact that the contribution of smaller droplets generated during the break-up is relatively small and can be ignored. In addition, (9) implies that droplets preserve their spherical shape during the break-up process. The authors agree that this is a limitation of the model. Combination of solutions for (9) together with (3a), (3b), or (3c) associated with spray penetration for Stokes, Allen, and Newton flows will be investigated for the bag and stripping break-up regimes.

\section{Effect of Droplet Bag Break-Up}

From (5), the following is obtained:

$$
r_{d b}=\frac{6 \sigma}{\rho_{g} v_{d}^{2}}
$$

Substituting (7) into (9), the following equation is obtained:

$$
\frac{d r}{d t}=-\frac{r-r_{d b}}{a_{b} r^{3 / 2}}
$$

where $a_{b}=D \sqrt{\rho_{d} / 2 \sigma}$ from (11) is valid for $r>r_{d b}$. Otherwise $r=$ const.

Assuming that $r \gg r_{d b}$ the right hand side of (11) can be reduced to $-1 /\left(a_{b} \sqrt{r}\right)$ and a definition can be written as

$$
r=r_{d 0}\left(1-a_{r b} t\right)^{2 / 3}, \quad a_{r b}=\frac{3}{2 a_{b} r_{d 0}^{3 / 2}} .
$$

Substituting (12) into (3a), (3b), and (3c), we obtain the governing equation for Stokes, Allen, and Newton flows that are achieved as follows, respectively:

$$
\begin{gathered}
\frac{d^{2} s}{d t^{2}}+\frac{a_{e}}{\left(1-a_{r b} t\right)^{4 / 3}}\left(\frac{d s}{d t}\right)-k_{e} \frac{a_{e}}{\left(1-a_{r b} t\right)^{5 / 3}} \sqrt{s}=0 \\
\frac{d^{2} s}{d t^{2}}+\frac{b_{e}}{\left(1-a_{r b} t\right)^{1.066}}\left(\frac{d s}{d t}\right)^{1.4} \\
-1.4 k_{e} \frac{b_{e}}{\left(1-a_{r b} t\right)^{1.3993}} \sqrt{s}\left(\frac{d s}{d t}\right)^{0.4}=0 \\
\frac{d^{2} s}{d t^{2}}+\frac{c_{e}}{\left(1-a_{r b} t\right)^{2 / 3}}\left(\frac{d s}{d t}\right)^{2}-2 k_{e} \frac{c_{e}}{\left(1-a_{r b} t\right)} \sqrt{s}\left(\frac{d s}{d t}\right)=0
\end{gathered}
$$

where $a_{e}=9 \mu_{g} / 2 r_{d 0}^{2} \rho_{d}, b_{e}=4.577 \mu_{g}^{0.6} \rho_{g}^{0.4} / r_{d 0}^{1.6} \rho_{d}$, and $c_{e}=$ $0.165 \rho_{g} / r_{d 0} \rho_{d}$.

A careful examination of above equations revealed that they could be combined to give the following model:

$$
\begin{aligned}
& \frac{d^{2} s}{d t^{2}}+\frac{\rho_{e \eta}}{\left(1-a_{r b} t\right)^{\varepsilon}}\left(\frac{d s}{d t}\right)^{\eta+1} \\
& -(\eta+1) k_{e} \frac{\rho_{e \eta}}{\left(1-a_{r b} t\right)^{\varepsilon+1 / 3}} \sqrt{s}\left(\frac{d s}{d t}\right)^{\eta}=0 .
\end{aligned}
$$

Here $\eta$ is defined as the flow regime parameter or identifier. Equation (14) is a new unified model to explain the droplet bag break-up and air entrainment impact at initial stages of fuel spray penetration, noting that it has not been reported elsewhere in literature to the best of the author's knowledge. The equation is nonlinear and embraces all three regimes of the flow in which we have $\varepsilon=4 / 3,1.0666$, and $2 / 3$. One has to note that the parameter $\eta$ takes the values of $0,0.4$, and 1 such that $\rho_{e 0}=a_{e}$ (Stokes flow), $\rho_{e 0.4}=b_{e}$ (Allen flow), and $\rho_{e 1}=$ $c_{e}$ (Newton flow), respectively. This means that the specific applicable examples to (3a), (3b), and (3c) are embedded in the model equation (14), respectively.

\section{Effect of Droplet Stripping Break-Up}

From (6) the following can be achieved:

$$
r_{d s}=\frac{b_{s}}{v_{d}^{3}}, \quad b_{s}=\frac{\sigma^{2}}{2 \rho_{g} \mu_{g}} .
$$

The combination of (8), (9), and (15) yields

$$
\frac{d r}{d t}=-\frac{r v_{d}-\left(b_{s} / v_{d}^{2}\right)}{c_{s} r}
$$

where $c_{s}=C \sqrt{\rho_{d} / \rho_{g}}$ in (16) is valid for $r>r_{d s}$. Otherwise $r=$ const.

Assuming that $r \gg r_{d s}$, the right hand side of (16) can be simplified to $-v_{d} / c_{s}$. The contribution of the term 
proportional to $b_{s}$ can be studied similarly to Section 3 . In contrast to the case of bag break-up, this equation cannot be solved unless we know the time dependence of $v_{d}$.

Considering the combination of (3a), (3b), and (3c) and (16) with $r>r_{d s}$ assumption, the governing equations for Stokes, Allen, and Newton flows are written in the following order:

$$
\begin{aligned}
& \frac{d^{2} s}{d t^{2}}+\frac{a_{\eta e} r_{0}^{2}}{\left(r_{0}-s(t) / c_{s}\right)^{2}}\left(\frac{d s}{d t}\right) \\
& \quad-k_{e} \frac{a_{\eta e} r_{0}^{5 / 2}}{\left(r_{0}-s(t) / c_{s}\right)^{5 / 2}} \sqrt{s}=0, \\
& \frac{d^{2} s}{d t^{2}}+\frac{b_{\eta e} r_{0}^{1.6}}{\left(r_{0}-s(t) / c_{s}\right)^{1.6}}\left(\frac{d s}{d t}\right)^{1.4} \\
& -1.4 k_{e} \frac{b_{\eta e} r_{0}^{2.1}}{\left(r_{0}-s(t) / c_{s}\right)^{2.1}} \sqrt{s}\left(\frac{d s}{d t}\right)^{0.4}=0, \\
& \frac{d^{2} s}{d t^{2}}+\frac{c_{\eta e} r_{0}}{\left(r_{0}-s(t) / c_{s}\right)}\left(\frac{d s}{d t}\right)^{2} \\
& -2 k_{e} \frac{c_{\eta e} r_{0}^{3 / 2}}{\left(r_{0}-s(t) / c_{s}\right)^{3 / 2}} \sqrt{s}\left(\frac{d s}{d t}\right)=0 .
\end{aligned}
$$

A careful examination of (17) revealed that they could be combined to give the model:

$$
\begin{aligned}
& \frac{d^{2} s}{d t^{2}}+\frac{\alpha_{\eta e} r_{0}^{\varepsilon}}{\left(r_{0}-s(t) / c_{s}\right)^{\varepsilon}}\left(\frac{d s}{d t}\right)^{\eta+1} \\
& -(\eta+1) k_{e} \frac{\alpha_{\eta e} r_{0}^{\varepsilon+1 / 2}}{\left(r_{0}-s(t) / c_{s}\right)^{\varepsilon+1 / 2}} \sqrt{s}\left(\frac{d s}{d t}\right)^{\eta}=0 .
\end{aligned}
$$

Here $\eta$ is defined as the flow regime parameter or identifier. Equation (18) is a new unified model to explain the droplet stripping break-up and air entrainment impact at initial stages of the fuel spray penetration. Note that (18) has not been reported elsewhere in the literature to the best of the author's knowledge. The equation is nonlinear and embraces all three regimes of the flow in that $\varepsilon=2,1.6$, and 1 while the parameter $\eta$ takes the values $0,0.4$, and 1 such that $\alpha_{e 0}=a_{e}$ (Stokes flow), $\alpha_{e 0.4}=b_{e}$ (Allen flow), and $\alpha_{e 1}=c_{e}$ (Newton flow), respectively. This means that the specific applicable examples to (3a), (3b), and (3c) are embedded in the model equation (18), respectively.

\section{Basic Ideas of the HPM}

To illustrate the basic idea of this method $[9,10]$, we consider the following nonlinear differential equation:

$$
A(u)-f(r)=0, \quad r \in \Omega .
$$

Consider the boundary given as

$$
B\left(u, \frac{\partial u}{\partial n}\right)=0, \quad r \in \Gamma,
$$

where $A$ is a general differential operator, $B$ a boundary operator, $f(r)$ a known analytical function, and $\Gamma$ the boundary of the domain $\Omega$. The operator $A$ can be divided into two parts of $L$ and $N$, where $L$ is the linear part, whereas $N$ is a nonlinear section in (19): therefore, it can be represented as follows:

$$
L(u)+N(u)-f(r)=0, \quad r \in \Omega .
$$

The homotopy perturbation structure is shown as

$$
H(\nu, p)=(1-p)\left[L(\nu)-L\left(u_{0}\right)\right]+p[A(\nu)-f(r)]=0,
$$

where

$$
\nu(r, p): \Omega \times[0,1] \longrightarrow R .
$$

We can assume that the solution of (23) can be written as a power series in $p$ as follows:

$$
\nu=v_{0}+\varepsilon \nu_{1}+\varepsilon^{2} \nu_{2}+\cdots
$$

Setting $p=1$ results in the approximate solution as

$$
V=\lim _{p \rightarrow 1} v=v_{0}+v_{1}+v_{2}+\cdots
$$

The combination of the perturbation method and the homotopy method is called the HPM, which lacks the limitations of the traditional perturbation methods, although this technique has full advantages of the traditional perturbation techniques.

\section{Homotopy Perturbation Method Solution}

In this section, we will apply the homotopy perturbation method (HPM) to nonlinear ordinary differential equation (14) and (18). According to this method, we can construct a homotopy as follows:

$$
\begin{aligned}
H(\phi, p)= & (1-p) L(\phi) \\
+ & p\left(\frac{d^{2} \phi}{d t^{2}}+\frac{\alpha_{\eta e}}{\left(1-a_{r b} t\right)^{\varepsilon}}\left(\frac{d \phi}{d t}\right)^{\eta+1}\right. \\
& \left.\quad(\eta+1) k_{e} \frac{\alpha_{\eta e}}{\left(1-a_{r b} t\right)^{\varepsilon+1 / 3}} \sqrt{\phi}\left(\frac{d \phi}{d t}\right)^{\eta}\right),
\end{aligned}
$$

$$
\begin{aligned}
H(\phi, p)= & (1-p) L(\phi) \\
& +p\left(\frac{d^{2} \phi}{d t^{2}}+\frac{\alpha_{\eta e^{r}} r_{0}^{\varepsilon}}{\left(r_{0}-s(t) / c_{s}\right) \sqrt{\phi}(d \phi / d t)^{\eta^{\varepsilon}}}\right. \\
& \times\left(\frac{d \phi}{d t}\right)^{\eta+1}-(\eta+1) k_{e} \\
& \left.\times \frac{\alpha_{\eta e^{r_{0}^{\varepsilon+1 / 2}}}}{\left(r_{0}-s(t) / c_{s}\right)^{\varepsilon+1 / 2}}\right),
\end{aligned}
$$


where

$$
L(\phi)=\frac{d^{2} \phi}{d t^{2}} .
$$

Applying the perturbation technique $[9,10]$, we can assume that the solution of (26a) and (26b) can be expressed as a series in $p$ :

$$
\phi=\phi_{0}+p \phi_{1}+p^{2} \phi_{2}+\cdots,
$$

where $p \in[0,1]$ is an embedding parameter. Taking $p=0$, we obtain the initial guesses; in contrast having $p=1$ in (28) presents the original one.

Tuning $p=1$, we obtain an approximate solution of (26a) and (26b):

$$
s=\lim _{p \rightarrow 1} \phi=\phi_{0}+\phi_{1}+\phi_{2}+\cdots
$$

One has to substitute (29) into the governing equation (26a) and (26b), then collects the powers of $p$, and finally obtains a sequence of differential equations and boundary conditions. The solution for the spray penetration for Stokes, Allen, and Newton flows for droplet bag and stripping break-up regimes is given as follows.

Bag break-up for stokes flow is as follows:

$$
\begin{aligned}
s(t)=- & 0.00186 \alpha_{e 0} k_{e} a_{r b}^{2} v_{d 0}^{4} t^{8} \\
+ & \left(0.010582 \alpha_{e 0} k_{e} a_{r b}^{2} v_{d 0}^{3}-0.0093 \alpha_{e 0} k_{e} a_{r b} v_{d 0}^{4}\right) t^{7} \\
+ & \left(0.05 \alpha_{e 0} k_{e} a_{r b} v_{d 0}^{3}-0.02546 \alpha_{e 0} k_{e} a_{r b}^{2} v_{d 0}^{2}\right. \\
& \left.-0.0078125 \alpha_{e 0} k_{e} v_{d 0}^{4}\right) t^{6} \\
+ & \left(0.05 \alpha_{e 0} k_{e} v_{d 0}^{3}+0.0416 \alpha_{e 0} k_{e} a_{r b}^{2} v_{d 0}\right. \\
& \left.-0.1432 \alpha_{e 0} k_{e} a_{r b} v_{d 0}^{2}\right) t^{5} \\
+ & \left(0.260416 \alpha_{e 0} k_{e} a_{r b} v_{d 0}-0.14322 \alpha_{e 0} k_{e} v_{d 0}^{2}\right. \\
& \left.+0.00289 \alpha_{e 0} k_{e} a_{r b}^{2}\right) t^{4} \\
+ & \left(0.0217 \alpha_{e 0} k_{e} a_{r b}-0.2 a_{e} a_{r b} v_{d 0}\right. \\
& \left.+0.3125 \alpha_{e 0} k_{e} v_{d 0}\right) t^{3} \\
+ & \left(-0.5 \alpha_{e 0} v_{d 0}+0.03906 \alpha_{e 0} k_{e}\right) t^{2} .
\end{aligned}
$$

Bag break-up for Allen flow:

$$
\begin{aligned}
s(t)= & -0.0000678 k_{e} a_{r b}^{2} v_{d 0}^{7} \eta^{11} \\
+ & \left(0.00075841 k_{e} a_{r b}^{2} v_{d 0}^{6}-0.000326 k_{e} a_{r b} v_{d 0}^{7}\right) t^{10} \\
+ & \alpha_{e 0.4}\left(-0.0002916 k_{e} a_{r b} v_{d 0}^{7}-0.00426 k_{e} a_{r b}^{2} v_{d 0}^{5}\right. \\
& \left.+0.003732 k_{e} a_{r b} v_{d 0}^{6}\right) t^{9} \\
+ & \alpha_{e 0.4}\left(0.00342 k_{e} v_{d 0}^{6}-0.021595 k_{e} a_{r b} v_{d 0}^{5}\right. \\
& \left.+0.012362 k_{e} a_{r b}^{2} v_{d 0}^{4}\right) t^{8} \\
+ & \alpha_{e 0.4}\left(-0.02056 k_{e} v_{d 0}^{5}+0.0649 k_{e} a_{r b} v_{d 0}^{4}\right. \\
& \left.-0.01889 k_{e} a_{r b}^{2} v_{d 0}^{3}\right) t^{7} \\
+ & \alpha_{e 0.4}\left(0.01361 k_{e} a_{r b}^{2} v_{d 0}^{2}-0.1041 k_{e} a_{r b} v_{d 0}^{3}\right. \\
& \left.+0.00199 a_{r b} v_{d 0}^{3}+0.06490 k_{e} v_{d 0}^{4}\right) t^{6} \\
+ & \left(-0.11158 k_{e} v_{d 0}^{3}-0.02389 a_{r b} v_{d 0}^{2}+0.0028 v_{d 0}^{3}\right. \\
& \left.+0.021031 k_{e} a_{r b}^{2} v_{d 0}+0.08042 k_{e} a_{r b} v_{d 0}^{2}\right) t^{5} \\
+ & \alpha_{e 0.4}\left(-0.0373 v_{d 0}^{2}+0.001348 k_{e} a_{r b}^{2}+0.09573 k_{e} v_{d 0}^{2}\right. \\
+ & \left.+0.13801 k_{e} a_{r b} v_{d 0}-0.0597 a_{r b} v_{d 0}\right) t^{4} \\
+ & +\alpha_{e 0.4}\left(-0.112 v_{d 0}+0.01137 a_{r b}\right. \\
& \left.+0.19716 k_{e} v_{d 0}+0.010616 k_{e} a_{r b}\right) t^{3} \\
& \left(0.02275 k_{e}+0.032\right) t^{2} .
\end{aligned}
$$

Bag break-up for Newton flow:

$$
\begin{aligned}
s(t)= & 0.000214 \alpha_{e 1} v_{d 0}^{4} k_{e} a_{r b}^{4} t^{9} \\
+ & \alpha_{e 1}\left(-0.00137 v_{d 0}^{3} k_{e} a_{r b}^{4}+0.00074 v_{d 0}^{4} k_{e} a_{r b}^{3}\right) t^{8} \\
+ & \alpha_{e 1}\left(0.00297 v_{d 0}^{4} k_{e} a_{r b}^{2}+0.00551 v_{d 0}^{2} k_{e} a_{r b}^{4}\right. \\
& \left.-0.00496 v_{d 0}^{3} k_{e} a_{r b}^{3}\right) t^{7} \\
+ & \alpha_{e 1}\left(-0.02083 v_{d 0}^{3} k_{e} a_{r b}^{2}+0.02083 v_{d 0}^{2} k_{e} a_{r b}^{3}\right. \\
+ & \left.0.00416 v_{d 0}^{4} k_{e} a_{r b}+0.0025 k_{e} v_{d 0} a_{r b}^{4}\right) t^{6} \\
+ & \alpha_{e 1}\left(0.010416 k_{e} v_{d 0} a_{r b}^{3}+0.09375 v_{d 0}^{2} k_{e} a_{r b}^{2}\right. \\
& \left.-0.03125 v_{d 0}^{3} k_{e} a_{r b}+0.00625 v_{d 0}^{4} k_{e}\right) t^{5} \\
+ & \alpha_{e 1}\left(-0.052083 v_{d 0}^{3} k_{e}-0.04629 v_{d 0}^{2} a_{r b}^{2}\right. \\
+ & \left.0.05208 k_{e} v_{d 0} a_{r b}^{2}+0.15625 v_{d 0}^{2} k_{e} a_{r b}\right) t^{4}
\end{aligned}
$$




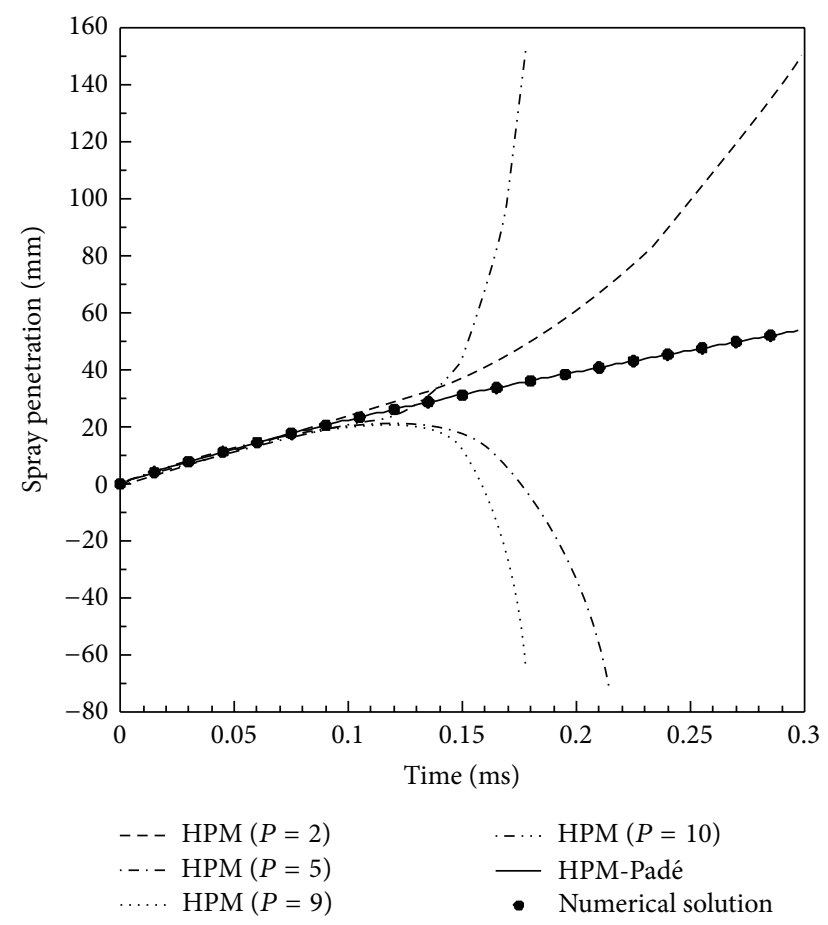

FIGURE 2: The effect of increasing the number of HPM terms in comparison with HPM-Padé [8/8] and numerical solution (RK4) for the spray penetration when $\rho_{g}=14.8 \mathrm{~kg} / \mathrm{m}^{3}, P_{\text {inj }}=170 \mathrm{Mpa}$.

$$
\begin{gathered}
+\alpha_{e 1}\left(0.10416 k_{e} v_{d 0} a_{r b}-0.11 v_{d 0}^{2} a_{r b}\right. \\
\left.+0.3125 v_{d 0}^{2} k_{e}\right) t^{3} \\
+\alpha_{e 1}\left(-0.5 v_{d 0}^{2}+0.3125 k_{e} v_{d 0}\right) t^{2}
\end{gathered}
$$

Stripping break-up for Stokes flow:

$$
\begin{aligned}
s(t)= & \frac{1}{672} \frac{\left(\alpha_{e 0} v_{d 0}^{5} k_{e}\right)}{\left(r_{0}^{2} c_{s}^{2}\right)}+\alpha_{e 0}\left(\frac{1}{192} \frac{v_{d 0}^{4} k_{e}}{\left(r_{0} c_{s}\right)}-\frac{1}{96} \frac{v_{d 0}^{4} k_{e}}{\left(r_{0}^{2} c_{s}^{2}\right)}\right) t^{6} \\
& +\alpha_{e 0}\left(\frac{3}{64} \frac{v_{d 0}^{3} k_{e}}{\left(r_{0}^{2} c_{s}^{2}\right)}+\frac{1}{320} a_{e} v_{d 0}^{3} k_{e}-\frac{5}{128} \frac{v_{d 0}^{3} k_{e}}{\left(r_{0} c_{s}\right)}\right) t^{5} \\
& +\alpha_{e 0}\left(\frac{5}{192} \frac{v_{d 0}^{2} k_{e}}{\left(r_{0}^{2} c_{s}^{2}\right)}+\frac{25}{128} \frac{v_{d 0}^{2} k_{e}}{\left(r_{0} c_{s}\right)}-\frac{5}{192} v_{d 0}^{2} k_{e}\right) t^{4} \\
& +\alpha_{e 0}\left(\frac{5}{32} a_{e} v_{d 0} k_{e}+\frac{25}{192} \frac{v_{d 0} k_{e}}{\left(r_{0} c_{s}\right)}-\frac{1}{3} \frac{v_{d 0}^{2}}{\left(r_{0} c_{s}\right)}\right) t^{3} \\
& +\alpha_{e 0}\left(-\frac{1}{2} v_{d 0}+\frac{5}{32} k_{e}\right) t^{2} .
\end{aligned}
$$

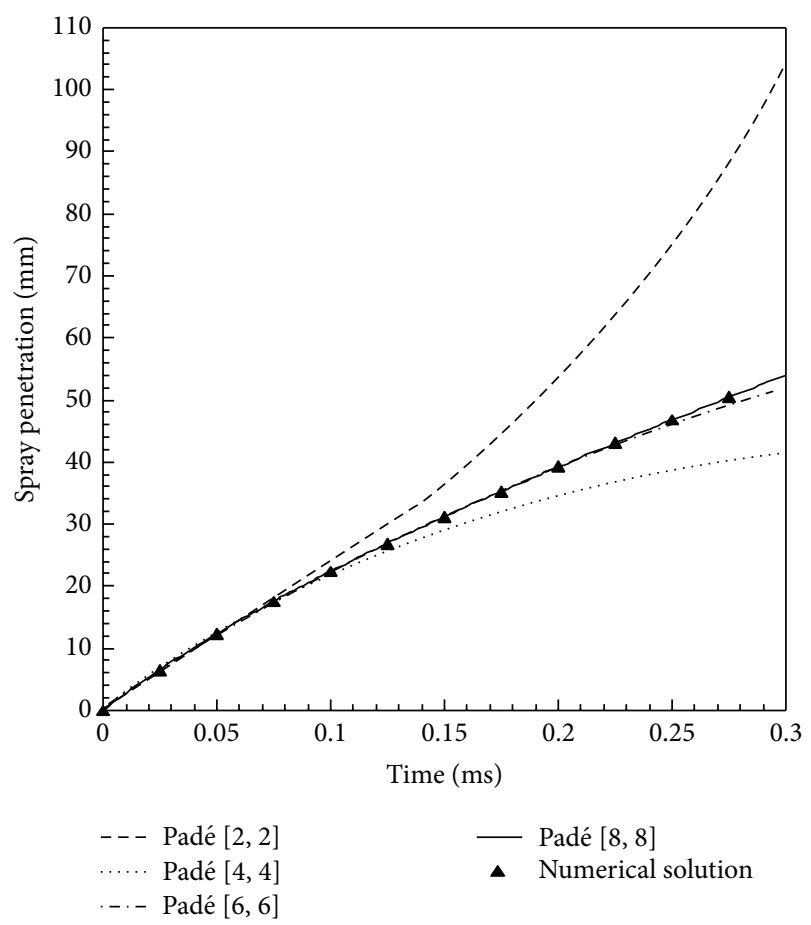

Figure 3: The effect of increasing the order of Padé approximation on the spray penetration when $\rho_{g}=14.8 \mathrm{~kg} / \mathrm{m}^{3}, P_{\text {inj }}=170 \mathrm{Mpa}$.

Stripping break-up for Allen flow:

$$
\begin{aligned}
& s(t)=\frac{\left(0.0000497 \alpha_{e 0.4} v_{d 0}^{8} k_{e} \eta^{10}\right)}{\left(r_{0}^{2} c_{s}^{2}\right)} \\
& +\alpha_{e 0.4}\left(-\frac{\left(0.000614 v_{d 0}^{7} k_{e}\right)}{\left(r_{0}^{2} c_{s}^{2}\right)}+\frac{\left(0.000163 v_{d 0}^{7} k e\right)}{\left(r_{0} c_{s}\right)}\right) t^{9} \\
& +\alpha_{e 0.4}\left(-\frac{\left(0.00207375 v_{d 0}^{6} k_{e}\right)}{\left(r_{0} c_{s}\right)}+0.0001 k_{e} v_{d 0}^{6}\right. \\
& \left.+\frac{\left(0.00419 v_{d 0}^{6} k_{e}\right)}{\left(r_{0}^{2} c_{s}^{2}\right)}\right) t^{8} \\
& +\alpha_{e 0.4}\left(\frac{\left(0.01466 v_{d 0}^{5} k_{e}\right)}{\left(r_{0} c_{s}\right)}-0.001316 k_{e} v_{d 0}^{5}\right. \\
& \left.-\frac{\left(0.013506 v_{d 0}^{5} k_{e}\right)}{\left(r_{0}^{2} c_{s}^{2}\right)}\right) t^{7} \\
& +\alpha_{e 0.4}\left(-\frac{\left(0.04963 v_{d 0}^{4} k_{e}\right)}{\left(r_{0} c_{s}\right)}+\frac{\left(0.020626 v_{d 0}^{4} k_{e}\right)}{\left(r_{0}^{2} c_{s}^{2}\right)}\right. \\
& \left.+\frac{\left(0.002986 v_{d 0}^{4}\right)}{\left(r_{0} c_{s}\right)}+0.009776 k_{e} v_{d 0}^{4}\right) t^{6}
\end{aligned}
$$



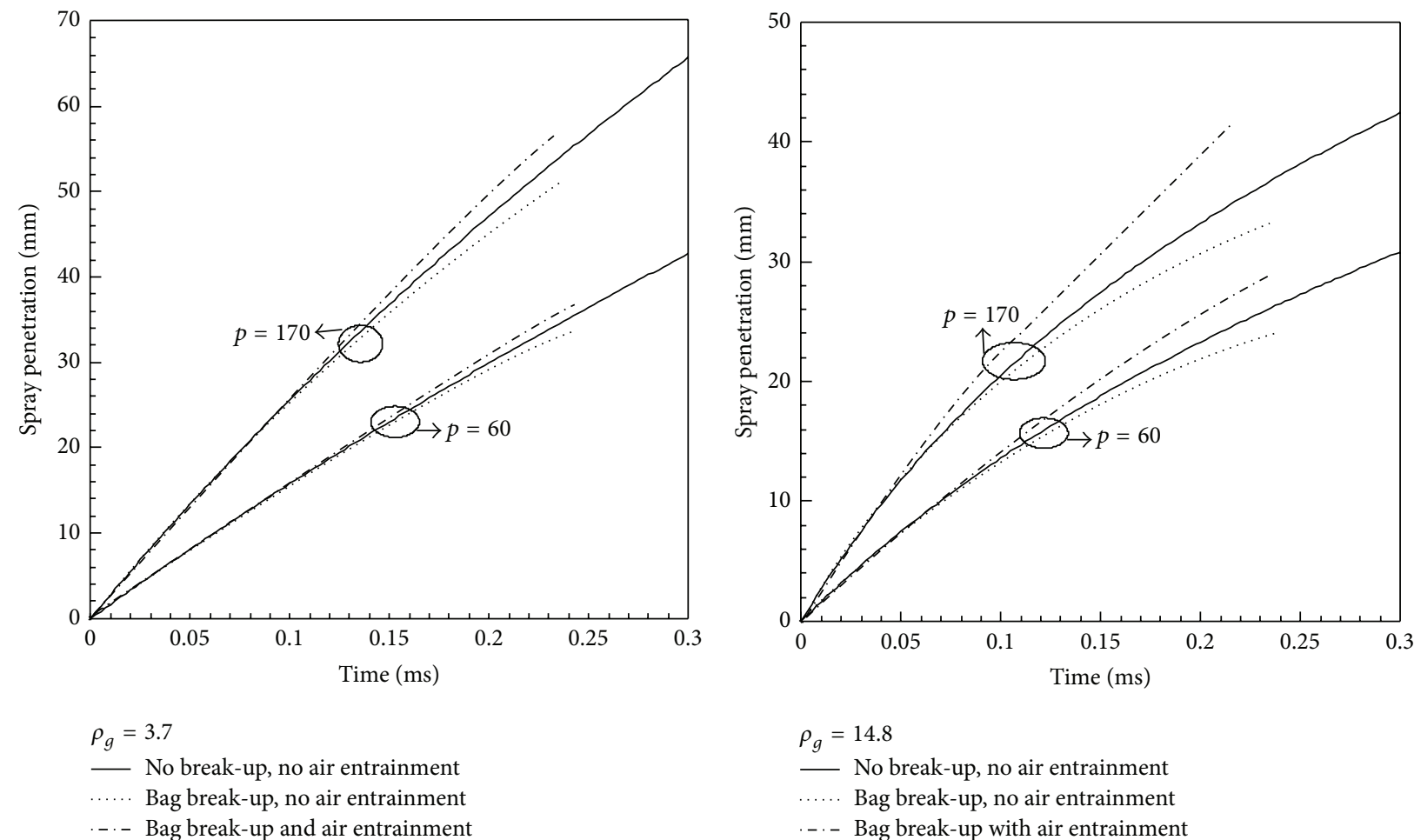

$$
\begin{aligned}
& \rho_{g}=3.7 \\
& - \text { No break-up, no air entrainment } \\
& \text {.... Bag break-up, no air entrainment } \\
& \text {..- Bag break-up and air entrainment }
\end{aligned}
$$

(a) (b)

FIGURE 4: The variation of spray penetration length with time in the cases when no break-up and air entrainment are taken into account; bag break-up is taken into account; both bag break-up and air entrainment are taken into account: (a) refers to $\rho_{g}=3.7 \mathrm{~kg} / \mathrm{m}^{3}, P_{\text {inj }}=60$, and $170 \mathrm{MPa}$ and (b) refers to $\rho_{g}=14.8 \mathrm{Kg} / \mathrm{m}^{3}, P_{\text {inj }}=60$ and $170 \mathrm{MPa}$.

$$
\begin{aligned}
& +\alpha_{e 0.4}\left(0.0028 v_{d 0}^{3}+\frac{\left(0.0364 v_{d 0}^{3} k_{e}\right)}{\left(r_{0}^{2} c_{s}^{2}\right)}\right. \\
& -0.035455 k_{e} v_{d 0}^{3}-\frac{\left(0.03584 v_{d 0}^{3}\right)}{\left(r_{0} c_{s}\right)} \\
& \left.+\frac{\left(0.0812175 v_{d 0}^{3} k_{e}\right)}{\left(r_{0} c_{s}\right)}\right) t^{5} \\
& +\alpha_{e 0.4}\left(-0.0373 v_{d 0}^{2}+\frac{\left(0.01213 k_{e} v_{d 0}^{2}\right)}{\left(r_{0}^{2} c_{s}^{2}\right)}\right. \\
& -\frac{\left(0.0896 v_{d 0}^{2}\right)}{\left(r_{0} c_{s}\right)}+\frac{\left(0.15925 k_{e} v_{d 0}^{2}\right)}{\left(r_{0} c_{s}\right)} \\
& \left.+0.064458 k_{e} v_{d 0}^{2}\right) t^{4} \\
& +\alpha_{e 0.4}\left(\frac{\left(0.0637 k_{e} v_{d 0}\right)}{\left(r_{0} c_{s}\right)}-0.112 v_{d 0}\right. \\
& \left.+\frac{\left(0.01706 v_{d 0}\right)}{\left(r_{0} c_{s}\right)}+0.1516 k_{e} v_{d 0}\right) t^{3} \\
& +\alpha_{e 0.4}\left(0.091 k_{e}+0.032\right) t^{2} \text {. }
\end{aligned}
$$

Stripping break-up for Newton flow:

$$
\begin{aligned}
s(t)= & \frac{1}{672} \frac{\left(c_{e} v_{d 0}^{6} k_{e} \eta^{7}\right)}{\left(r_{0}^{2} c_{s}^{2}\right)} \\
+ & \left(\frac{1}{480} r_{0}^{3} c_{e} v_{d 0}^{5} k_{e} c_{s}^{3}-\frac{1}{96} \frac{\left(c_{e} v_{d 0}^{5} k_{e}\right)}{\left(r_{0}^{2} c_{s}^{2}\right)}\right. \\
& \left.+\frac{1}{240} \frac{\left(c_{e} v_{d 0}^{5} k_{e}\right)}{\left(r_{0} c_{s}\right)}\right) \eta^{6} \\
+ & \frac{1}{160} r_{0}^{4} c_{e} v_{d 0}^{4} k_{e} c_{s}^{4}-\frac{1}{32}\left(c_{e} v_{d 0}^{4} k_{e}\right) \\
& \left.+\frac{3}{64} \frac{\left(c_{e} v_{d 0}^{4} k_{e}\right)}{\left(r_{0}^{2} c_{s}^{2}\right)}-\frac{1}{64} r_{0}^{3} c_{e} v_{d 0}^{4} k_{e} c_{s}^{3}\right) \eta^{5} \\
+ & \left(\frac{5}{64} r_{0}^{3} c_{e} v_{d 0}^{3} k_{e} c_{s}^{3}+\frac{5}{32} \frac{\left(c_{e} v_{d 0}^{3} k_{e}\right)}{\left(r_{0} c_{s}\right)}\right. \\
& \left.+\frac{5}{192} \frac{c_{e} v_{d 0}^{3} k_{e}}{r_{0}^{2} c_{s}^{2}}-\frac{5}{96} r_{0}^{4} c_{e} v_{d 0}^{3} k_{e} c_{s}^{4}\right) \eta^{4}
\end{aligned}
$$




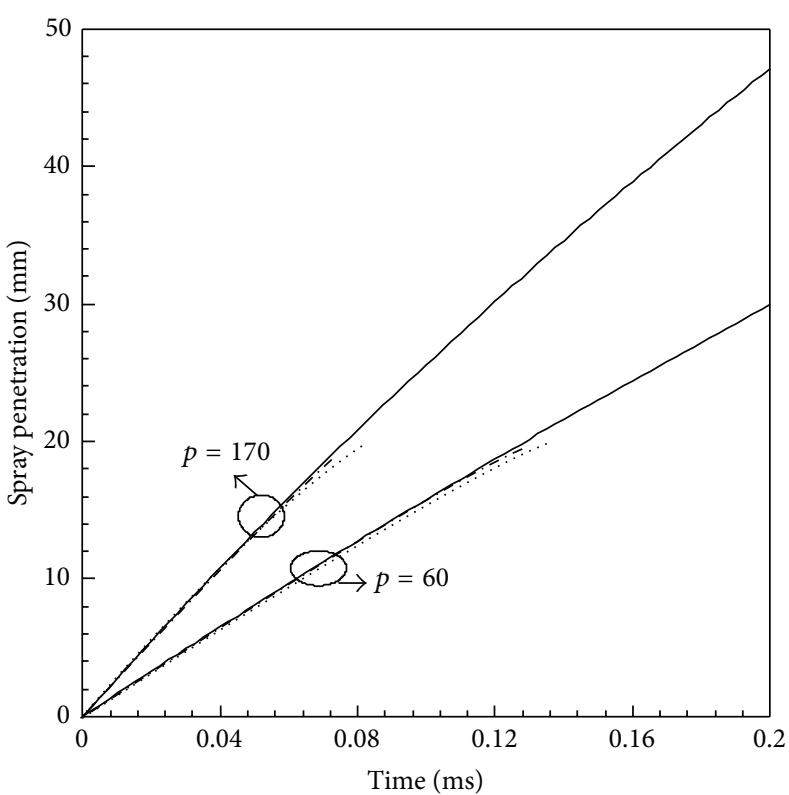

$\rho_{g}=3.7$

- No break-up, no air entrainment

Stripping break-up, no air entrainment

- . - Stripping break-up and air entrainment

(a)

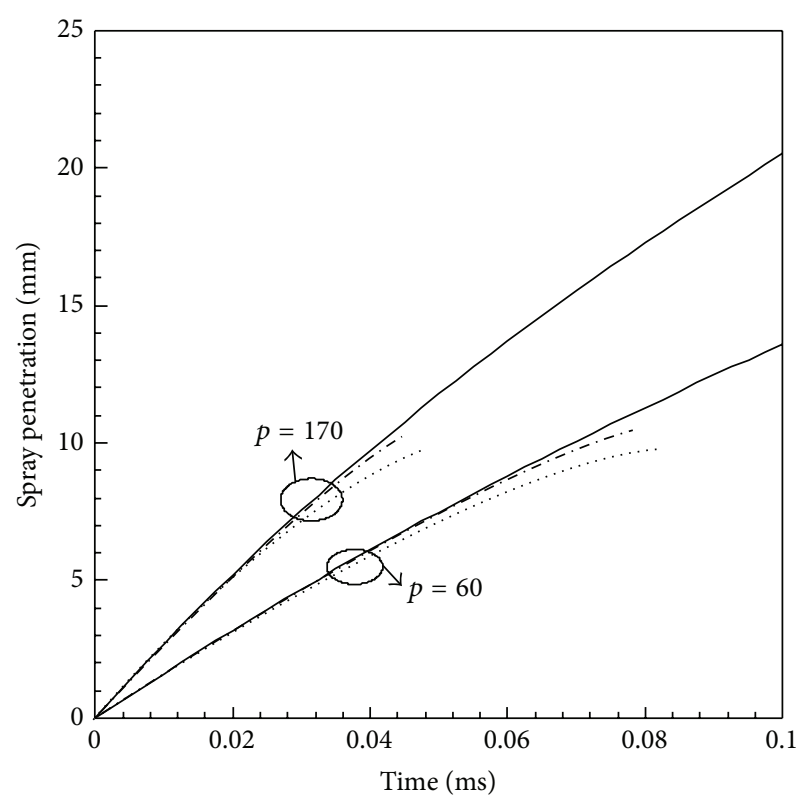

$\rho_{g}=14.8$

- No break-up, no air entrainment

..... Stripping break-up, no air entrainment

...- Stripping break-up and air entrainment

(b)

FIGURE 5: The variation of spray penetration length with time in the cases when no break-up and air entrainment are taken into account; stripping break-up is taken into account; stripping break-up and air entrainment are taken into account: (a) refers to $\rho_{g}=3.7 \mathrm{Kg} / \mathrm{m}^{3}, p=60$, and $170 \mathrm{MPa}$ and (b) refers to $\rho_{g}=14.8 \mathrm{Kg} / \mathrm{m}^{3}, p=60$, and $170 \mathrm{MPa}$.

$$
\begin{aligned}
& +\left(\frac{5}{48} \frac{\left(c_{e} v_{d 0}^{2} k_{e}\right)}{\left(r_{0} c_{s}\right)}-\frac{1}{6} \frac{\left(c_{e} v_{d 0}^{3}\right)}{\left(r_{0} c_{s}\right)}+\frac{5}{96} r_{0}^{3} c_{e} v_{d 0}^{2} k_{e} c_{s}^{3}\right. \\
& \left.+\frac{5}{16} r_{0}^{4} c_{e} v_{d 0}^{2} k_{e} c_{s}^{4}\right) \eta^{3} \\
& +\left(-\frac{1}{2} c_{e} r_{0}^{4} c_{s}^{4} v_{d 0}^{2}+\frac{5}{16} k_{e} r_{0}^{4} c_{s}^{4} c_{e} v_{d 0}\right) \eta^{2} .
\end{aligned}
$$

According to the above equations, we get the solution for the spray penetration field for the three flow patterns and at two break-up regimes.

\section{Results and Discussion}

Spray penetration lengths are solved analytically using homotopy perturbation method (HPM) employing Padé technique. In this case, the droplet radius was $0.0001 \mathrm{~mm}$, droplet density was $830 \mathrm{~kg} / \mathrm{m}^{3}$. The radius of the air jet near the nozzle was $0.0001 \mathrm{~mm}$, radius of the spray was $0.0001 \mathrm{~mm}$, gas density was $19.7 \mathrm{~kg} / \mathrm{m}^{3}$, droplet mass fraction was $\alpha_{d}=0.001$, and the gas dynamic viscosity was $3.36 \times 10^{-6} \mathrm{~m}^{2} / \mathrm{s}$.

In spite of the advantages of homotopy perturbation method, it has some drawbacks as well. By using HPM, series were acquired (in practice a truncated series solution).
The question is put forward as to how close the function can be approximated from its series expansion. This is the point where Padé approximants come into play. A possible answer is to construct a rational function whose series expansion matches the original one as much as possible. Such rational functions are called Padé approximants. Therefore, series of Padé approximants were applied to the series solution to improve the accuracy and extend the convergence domain.

Figures 2-5 are plotted in order to confirm the reliability and accuracy of the HPM that is enhanced by the Padé approximants. By using Padé approximant, one can create a fraction with some polynomials in the numerator and some polynomials in the denominator. It is of great importance to know that this solution is practical only if the orders of the numerator and the denominator are the same (diagonal approximation). In this study, Maple program was efficiently utilized in order to obtain Padé approximants with different orders $[\mathrm{L} / \mathrm{M}]$.

Figure 2 elucidates the exact behaviors of spray penetration profiles that have been obtained by HPM-Padé in comparison to HPM. The results of HPM-Padé are in good agreement with numerical results. Furthermore, this figure indicates that increasing the number of HPM terms does not affect the convergence and these series diverge around infinity.

Figure 3 shows that the difference between numerical and HPM solutions depends on the order of Padé approximation. 


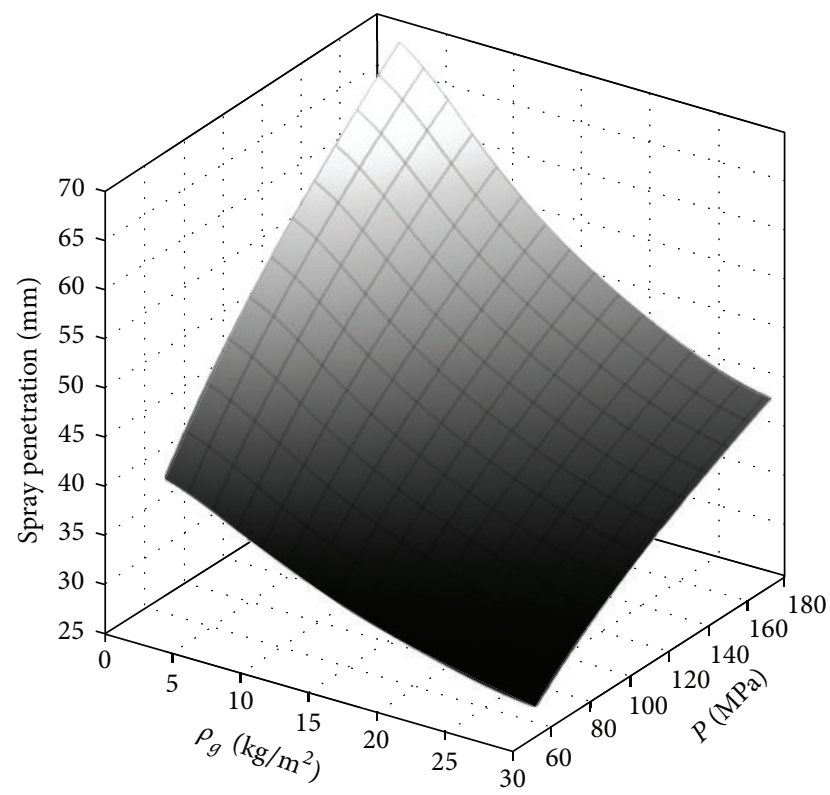

Figure 6: Contour plot for variation of the spray tip penetration with injection pressure and ambient density at constant hole diameter of $0.1 \mathrm{~mm}$ in $0.3 \mathrm{~ms}$.

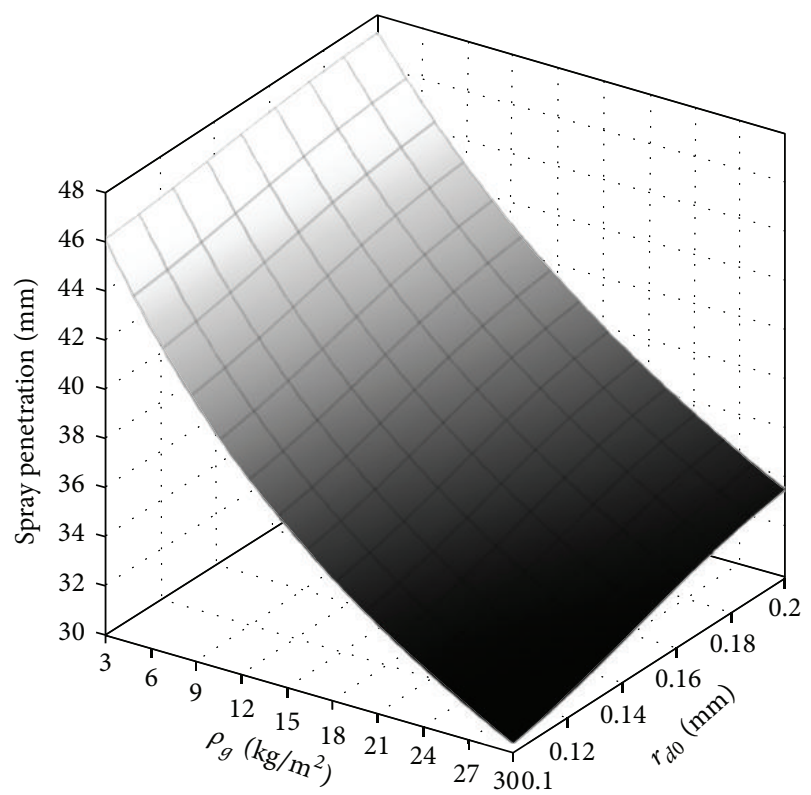

FIGURE 7: Contour plot for variation of the spray tip penetration with hole diameter and ambient density at constant injection pressure of $60 \mathrm{Mpa}$ in $0.3 \mathrm{~ms}$.

It can be concluded that higher degree of the Padé approximations provides highly accurate results in comparison to the numerical solution.

The results of the comparison are shown in Figures 4 and 5 for various gas and injection pressures. The plots are presented using the following approximations: neither breakup nor air entrainment are taken into account; break-up processes (bag and stripping) are taken into account, but

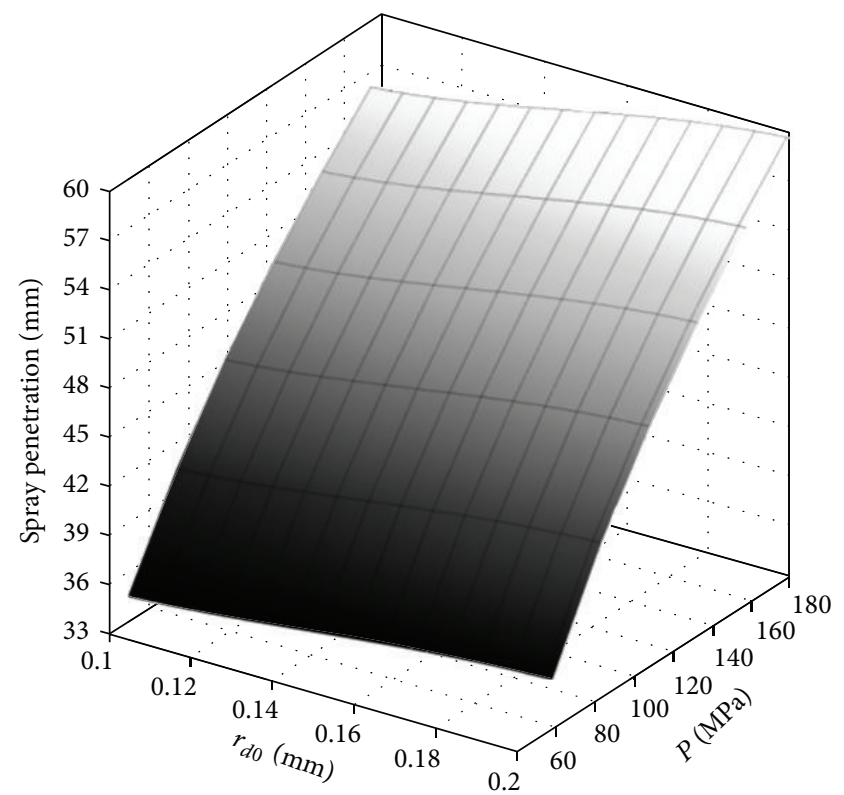

FIGURE 8: Contour plot for variation of spray tip penetration with nozzle-hole diameter and injection pressure at constant ambient density in $0.3 \mathrm{~ms}$ of $14.6 \mathrm{~kg} / \mathrm{m}^{3}$ in $0.3 \mathrm{~ms}$.

not air entrainment; both bag break-up and entrainment processes are taken into account. It is clear from these figures that spray tip penetration increases when higher injection pressure is applied. This is due to higher momentum of fuel jet. Moreover, the spray tip penetration decreases by consideration of the bag and stripping break-up effects.

All figures are presented in the validation range of the models; that is, $r \gg r_{d b(s)}$. (approximated as $r>3.3 r_{d b s}$ ) and $t<a_{r b s}^{-1}$. As can be noticed from our estimates, the range of validity for the stripping break-up model (about 0.05$0.1 \mathrm{~ms}$ ) is noticeably narrower than that of the bag break-up model (about $0.25 \mathrm{~ms}$ ). Hence, the plots are presented in two time ranges: $0-0.1$ and $0-0.3 \mathrm{~ms}$ for stripping and break-up models. Since the bag break-up model has a wider range of validity, the effect of air entrainment will be more important for this model. As it can be seen from Figures 4 and 5, in all of the cases that are presented with the simplest model (no break-up and air entrainment), it clearly underestimates the observed spray penetration lengths. Air entrainment leads to the increase of the spray penetration, while the break-up process tends to decrease the spray penetration. It can be inferred that these parameters have compensating influence on the spray penetration such that a tradeoff can be established between air entrainment and break-up to obtain an optimum spray penetration. At bag break-up model, the effect of air entrainment is higher than that of break-up effect. Therefore, air entrainment causes an increase in the spray tip penetration. Meanwhile, the effect of air entrainment is negligible in the stripping break up model; the effect of breakup is only important in spray tip penetration. The model is not valid at times greater than about $0.1-0.2 \mathrm{~ms}$ when the twophase flow approximation has to be used. 
Figures 6-8 illustrate the variation of spray tip penetration with nozzle-hole diameter, injection pressure, and ambient density as contour plots. As shown in Figure 6, when injection pressure increases and ambient density decreases at constant nozzle-hole diameter, spray tip penetration increases, noting that the effect of ambient density is more considerable. Also according to Figure 7, at constant injection pressure the spray tip penetration increases with the increase of nozzle-hole diameter and decrease of ambient density.

Figure 8 shows the variations of spray tip penetration with nozzle-hole diameter and injection pressure at constant ambient density. It is clear from Figure 8 that the effect of injection pressure is more considerable compared to the nozzle-hole diameter.

\section{Conclusions}

In this study, the unified model is proposed based on the droplet break-up and air entrainment influences at initial stage of the fuel spray penetration that accounts for three regimes of the flow. In the modeling equation, which is highly nonlinear, the effects of air entrainment and breakup processes on the spray penetration length were studied analytically in three flow regimes: Stokes, Allen, and Newton flows by homotopy perturbation method (HPM). The formulae for spray penetration length for three flows are presented at three cases: neither one of the break-up and air entrainment are taken into account; only breakup process (bag and stripping) is taken into account, but the air entrainment was disregarded; both break-up process (bag and stripping) and air entrainment are taken into account. The results show that the effect of air entrainment is more important in bag break-up mechanism than that of stripping break-up. The results of the analytical model are compared to the numerical method and a good agreement was accomplished. Moreover, the variations of the spray tip penetration with various parameters are 3 dimensionally plotted and commented upon. The models are expected to be valid in two time ranges: $0-0.1$ and $0-0.3 \mathrm{~ms}$ for stripping and bag break-up models after the start of injection.

\section{Conflict of Interests}

The authors declare that there is no conflict of interests regarding the publication of this paper.

\section{References}

[1] G. L. Borman and K. W. Ragland, Combustion Engineering, McGraw-Hill, New York, NY, USA, 1998.

[2] E. Loth, "Numerical approaches for motion of dispersed particles, droplets and bubbles," Progress in Energy and Combustion Science, vol. 26, no. 3, pp. 161-223, 2000.

[3] W. Hentschel, "Optical diagnostics for combustion process development of direct-injection gasoline engines," Proceedings of the Combustion Institute, vol. 28, no. 1, pp. 1119-1135, 2000.

[4] V. A. Iyer, J. Abraham, and V. Magi, "Exploring injected droplet size effects on steady liquid penetration in a diesel spray with a two-fluid model," International Journal of Heat and Mass Transfer, vol. 45, no. 3, pp. 519-531, 2002.

[5] J. Pozorski, S. Sazhin, M. Wacławczyk, C. Crua, D. Kennaird, and M. Heikal, "Spray penetration in a turbulent flow," Flow, Turbulence and Combustion, vol. 68, no. 2, pp. 153-165, 2002.

[6] G. M. Faeth, L.-P. Hsiang, and P.-K. Wu, "Structure and breakup properties of sprays," International Journal of Multiphase Flow, vol. 21, supplement, pp. 99-127, 1995.

[7] S. S. Sazhin, G. Feng, and M. R. Heikal, "A model for fuel spray penetration," Fuel, vol. 80, no. 15, pp. 2171-2180, 2001.

[8] S. Sazhin, C. Crua, D. Kennaird, and M. Heikal, "The initial stage of fuel spray penetration," Fuel, vol. 82, no. 8, pp. 875-885, 2003.

[9] J.-H. He, "Homotopy Perturbation technique," Computer Methods in Applied Mechanics and Engineering, vol. 178, no. 3-4, pp. 257-262, 1999.

[10] J.-H. He, "A coupling Method of a Homotopy Technique and a perturbation technique for non-linear problems," International Journal of Non-Linear Mechanics, vol. 35, no. 1, pp. 37-43, 2000.

[11] D. D. Ganji, M. J. Hosseini, and J. Shayegh, "Some nonlinear heat transfer equations solved by three approximate methods," International Communications in Heat and Mass Transfer, vol. 34, no. 8, pp. 1003-1016, 2007.

[12] M. Madani, M. Fathizadeh, Y. Khan, and A. Yildirim, "On the coupling of the Homotopy Perturbation Method and Laplace transformation," Mathematical and Computer Modelling, vol. 53, no. 9-10, pp. 1937-1945, 2011.

[13] Y. Khan, M. Akbarzade, and A. Kargar, "Coupling of homotopy and variational approach for conservative oscillator with strong odd-nonlinearity," Scientia Iranica, vol. 19, pp. 417-422, 2012.

[14] M. Dehghan, J. M. Heris, and A. Saadatmandi, "Application of semi-analytic methods for the Fitzhugh-Nagumo equation, which models the transmission of nerve impulses," Mathematical Methods in the Applied Sciences, vol. 33, no. 11, pp. 1384-1398, 2010.

[15] A. Yildirim, "Analytical approach to fractional partial differential equations in fluid mechanics by means of the Homotopy Perturbation Method," International Journal of Numerical Methods for Heat and Fluid Flow, vol. 20, no. 2, pp. 186-200, 2010.

[16] R. Grzymkowski, E. Hetmaniok, and D. Słota, "Application of the Homotopy Perturbation Method for calculation of the temperature distribution in thecast-mould heterogeneous domain," Journal of Achievements in Materials and Manufacturing Engineering, vol. 43, pp. 299-309, 2010.

[17] M. Dehghan and F. Shakeri, "Solution of a partial differential equation subject to temperature overspecification by He's Homotopy Perturbation Method," Physica Scripta, vol. 75, no. 6, pp. 778-787, 2007.

[18] F. Shakeri and M. Dehghan, "Inverse problem of diffusion equation by He's Homotopy Perturbation Method," Physica Scripta, vol. 75, no. 4, pp. 551-556, 2007.

[19] D. Slota, "The application of the Homotopy Perturbation Method to one-phase inverse Stefan problem," International Communications in Heat and Mass Transfer, vol. 37, no. 6, pp. 587-592, 2010.

[20] D. Słota, "Homotopy Perturbation Method for solving the twophase inverse stefan problem," Numerical Heat Transfer A: Applications, vol. 59, no. 10, pp. 755-768, 2011.

[21] E. Hetmaniok, I. Nowak, D. Słota, and R. Wituła, "Application of the Homotopy Perturbation Method for the solution of inverse heat conduction problem," International Communications in Heat and Mass Transfer, vol. 39, no. 1, pp. 30-35, 2012. 
[22] H. Jafari, M. Alipour, and H. Tajadodi, "Convergence of Homotopy Perturbation Method for solving integral equations," Thai Journal of Mathematics, vol. 8, pp. 511-520, 2010.

[23] H. Aminikhah and J. Biazar, "A new analytical method for solving systems of Volterra integral equations," International Journal of Computer Mathematics, vol. 87, no. 5, pp. 1142-1157, 2010.

[24] J. Biazar, B. Ghanbari, M. G. Porshokouhi, and M. G. Porshokouhi, "He's Homotopy Perturbation Method: a strongly promising method for solving non-linear systems of the mixed Volterra-Fredholm integral equations," Computers and Mathematics with Applications, vol. 61, no. 4, pp. 1016-1023, 2011.

[25] A. Golbabai and M. Javidi, "Application of He's Homotopy Perturbation Method for nth-order integro-differential equations," Applied Mathematics and Computation, vol. 190, no. 2, pp. 14091416, 2007.

[26] M. Dehghan and F. Shakeri, "Solution of an integro-differential equation arising in oscillating magnetic fields using He's Homotopy Perturbation Method," Progress in Electromagnetics Research, vol. 78, pp. 361-376, 2008.

[27] M. Ghasemi, M. T. Kajani, and E. Babolian, "Numerical solutions of the nonlinear Volterra-Fredholm integral equations by using Homotopy Perturbation Method," Applied Mathematics and Computation, vol. 188, no. 1, pp. 446-449, 2007.

[28] J. F. Douglas, J. M. Gasiorek, and J. A. Swaffield, Fluid Mechanics, Longman, London, UK, 1995.

[29] V. Ebrahimian, D. D. Ganji, and M. Esmaeipour, "Variational Iteration Method to investigate the initial stage of fuel spray penetration," International Journal of Dynamics of Fluids, vol. 4, pp. 109-119, 2008.

[30] P. Mebine, "A unified model for fuel spray penetration," Turkish Journal of Engineering and Environmental Sciences, vol. 36, pp. 219-225, 2012.

[31] A. A. Shraiber, A. M. Podvysotsky, and V. V. Dubrovsky, "Deformation and breakup of drops by aerodynamic forces," Atomization and Sprays, vol. 6, no. 6, pp. 667-692, 1996.

[32] N. Chigier and R. D. Reitz, "Regimes of jet breakup and breakup mechanisms (physical aspects)," in Recent Advances in Spray Combustion: Spray Atomization and Drop Burning Phenomena, K. Kuo Kenneth, Ed., pp. 109-135, American Institute of Aeronautics and Astronautics, 1998.

[33] S. P. Lin, "Regimes of jet breakup and breakup mechanisms (mathemat ical aspects)," in Recent Advances in Spray Combustion: Spray Atomization and Drop Burning Phenomena, K. Kuo Kenneth, Ed., pp. 137-160, American Institute of Aeronautics and Astronautics, 1998.

[34] M. Sevik and S. H. Park, "The splitting of drops and bubbles by turbulent fluid flow," ASME Journal of Fluids Engineering, vol. 95, no. 1, pp. 53-60, 1973.

[35] R. D. Reitz and R. Diwakar, "Effect of drop breakup on fuel sprays," SAE Report 860469, 1986.

[36] R. D. Reitz and R. Diwakar, "Structure of high-pressure fuel sprays," SAE Report 870598, 1987. 


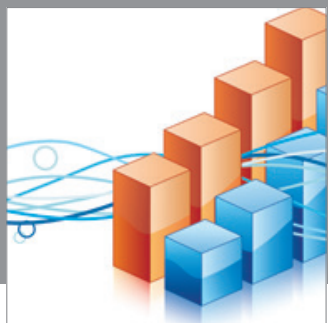

Advances in

Operations Research

mansans

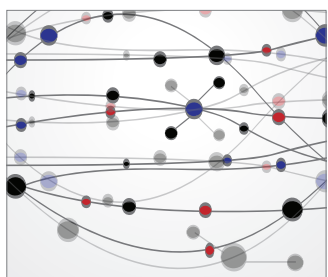

The Scientific World Journal
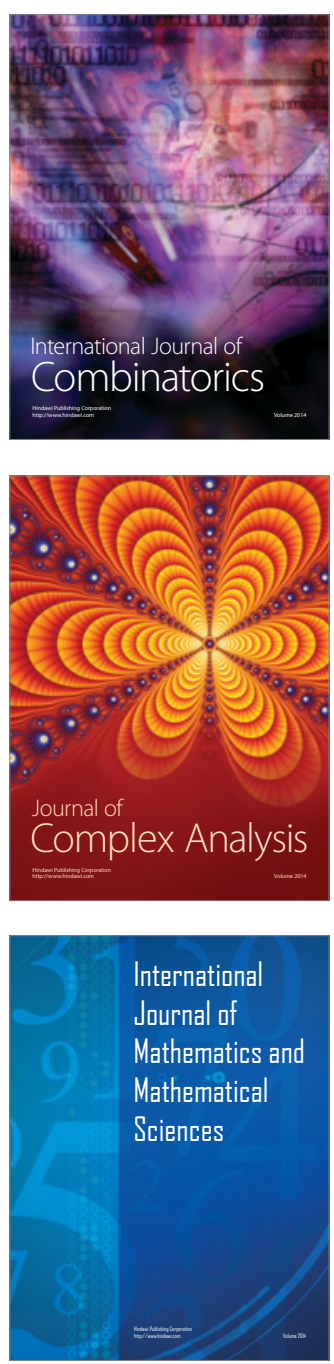
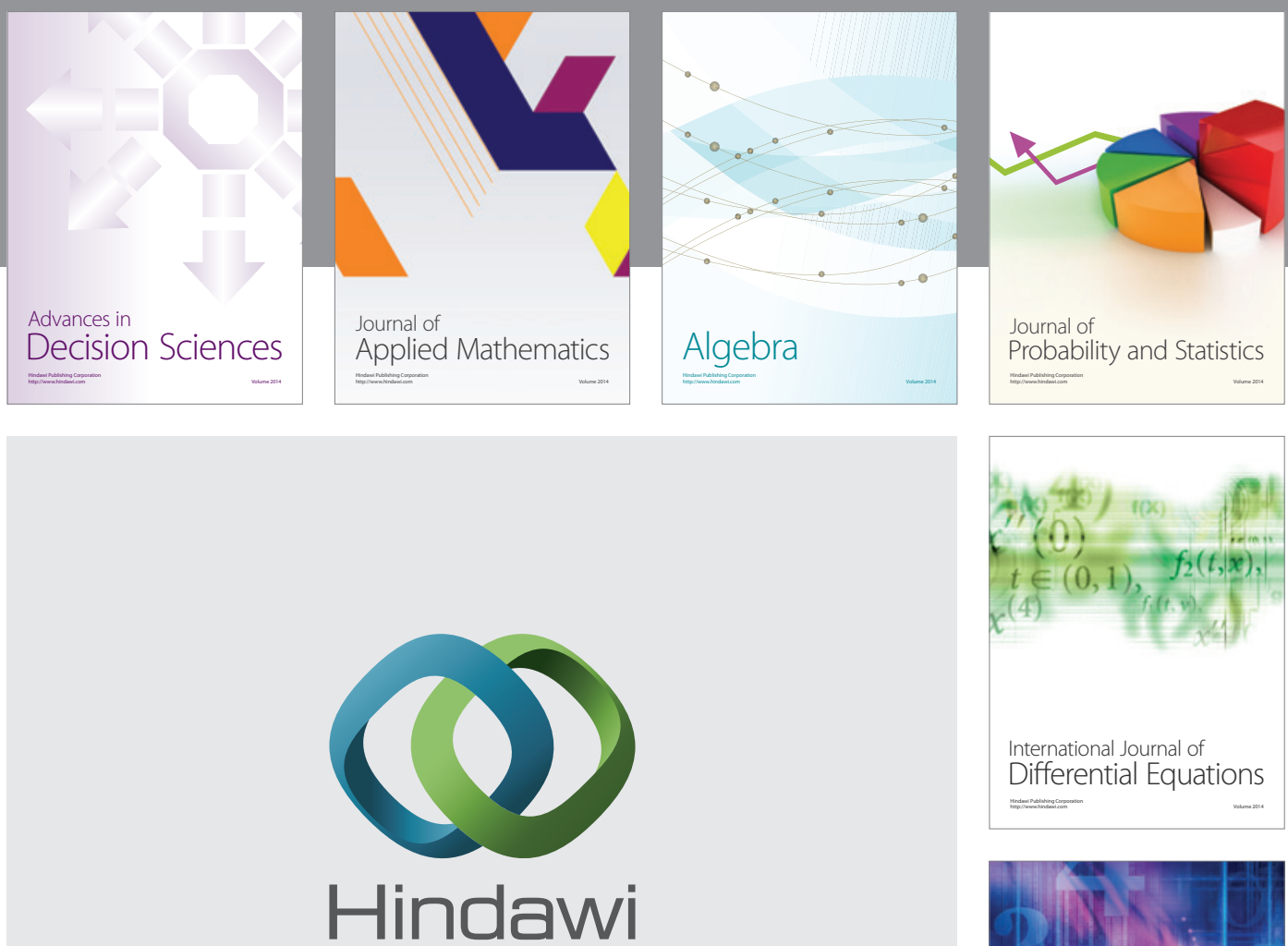

Submit your manuscripts at http://www.hindawi.com
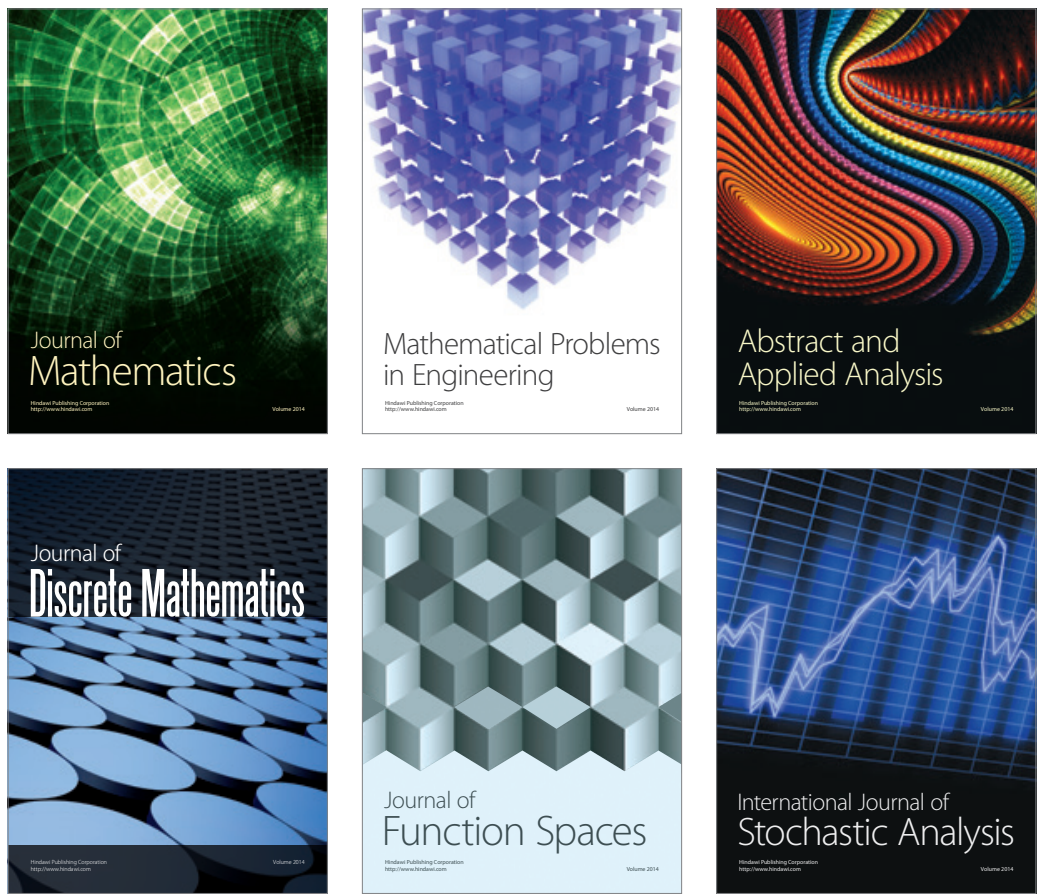

Journal of

Function Spaces

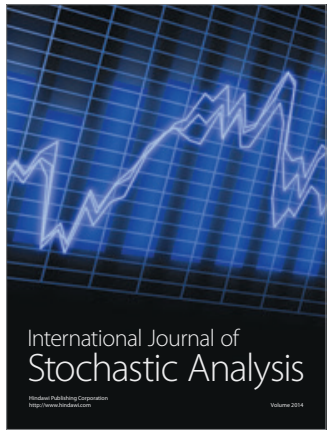

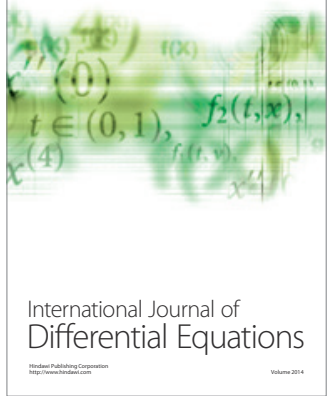
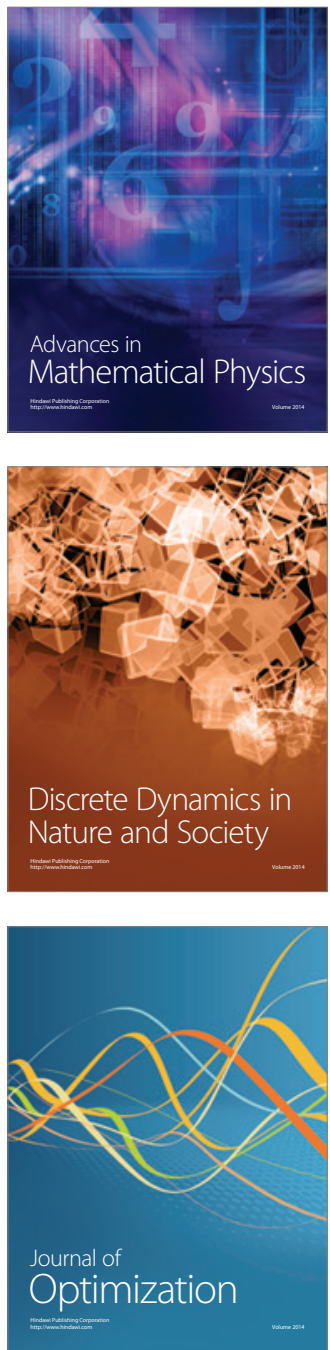